\title{
Preparing to Take the Field: A Temporal Exploration of Stress, Emotion, and Coping in Elite Cricket
}

\author{
Adam James Miles \\ Otago University \\ Rich Neil \\ Cardiff Metropolitan University \\ Jamie Barker \\ Staffordshire University
}

\begin{abstract}
The purpose of this study was to explore the stress, emotion, and coping (SEC) experiences of elite cricketers leading up to and on the day of their first competitive fixture of the season. Four elite male cricketers $(M=21.25, S D=1.5)$ completed Stress and Emotion Diaries (SEDs) for the 7-day period leading up to and on the day of their first competitive fixture of the season. We then interviewed the cricketers to explore the content of the SEDs in more detail. We used semistructured interviews to glean insight into the stressors, cognitions, emotions, coping strategies, and behaviors. Inductive and deductive content data analysis provided a holistic and temporal exploration of the SEC process underpinned by the cognitivemotivational-relational theory of emotions (Lazarus, 1999). The results highlighted the ongoing and continuous nature of the SEC process while illustrating the coping strategies the cricketers used leading up to and on the day of competition.
\end{abstract}

Keywords: appraisal, self-talk, social support

Contemporary research focusing on competition stress and emotion has been informed by Lazarus and Folkman's (1984) transactional perspective of stress and the cognitive-motivational-relational (CMR) theory of emotions (Lazarus, 1991, 1999, 2000). Essentially, Lazarus considered stress an ongoing transaction between the environmental demands and a person's resources, with the process of cognitive appraisal central to how the individual responds to transactions. This process involves both primary and secondary appraisals. Within primary appraisal, life events are constantly evaluated with respect to an individual's personal values, situational intentions, goal commitments, and well-being. Secondary appraisal refers to a cognitive-evaluative process that focuses on minimizing harm or maximizing gains in line with an individual's coping potential (Lazarus, 1991). Lazarus (1999, 2000) expanded this approach through the CMR theory of emotions and proposed that following the

Miles is with the School of Physical Education, Otago University, Dunedin, New Zealand. Neil is with the Cardiff School of Sport, Cardiff Metropolitan University, Cardiff, UK. Barker is with the Faculty of Health Sciences, Staffordshire University, Stoke-on-Trent, UK. Address appraisal process, emotional and behavioral responses (mediated by actual coping strategies) will have an influence on actual [sport] performance (Hanton, Neil, \& Mellalieu, 2008; Neil, Fletcher, Hanton, \& Mellalieu, 2007). For example, if an individual does not believe they have the resources to deal with the demands encountered in the competition environment, then he or she will perceive the situation as threatening or harmful and experience negative emotions such as anxiety and anger. This affective response may then be associated with negative behavior (e.g., physical tension) and performance (e.g., skill breakdown).

Lazarus further advocated that stress and emotion should be considered as one, coexisting, and interdependent process in the CMR theory of emotions. Based on his proposition, various types of stress appraisal (i.e., harm, benefit, challenge, or threat) were suggested to evoke different emotions. For example, an individual may

author correspondence to Adam James Miles at
adam.miles@postgrad.otago.ac.nz 
experience anxiety when a stressor is appraised as an uncertain threat, while anger may be experienced as a result of perceived personal harm. Thus an inability to cope with such emotions can distract athletes from the task at hand during sporting competition (Lazarus, 2000). Based on this notion, sport psychology researchers have explored the different coping strategies used by athletes (e.g., Nicholls \& Polman, 2007). In a systematic review on coping in sport, Nicholls and Polman reported five primary coping dimensions used by athletes: problem-focused coping (e.g., seeking information); emotion-focused coping (e.g., seeking emotional support); avoidance coping (e.g., removing oneself from the situation); approach coping (e.g., increasing effort); and appraisal coping (e.g., reevaluation of the situation).

Sport psychology researchers have explored the various coping strategies used by athletes in relation to numerous stressors (e.g., Devonport, Lane, \& Biscombe, 2013; Thelwell, Weston, \& Greenless, 2007; Weston, Thelwell, Bond, \& Hutchings, 2009). For example, Weston and colleagues (2009) examined the stressors and the coping strategies used by five elite single-handed sailors. They highlighted a variety of competitive, organizational, and personal stressors that were regulated through a number of coping responses (e.g., problem-, emotion-, appraisal-, and approach-focused coping). Similarly, Thelwell et al. (2007) explored the stressors experienced and coping strategies used by elite cricketers. Cricket, by its very nature, exposes players to a diversity of stressful situations that occur frequently over a period of hours and, sometimes, days. Given the duration at which cricket matches play-out, Thelwell and colleagues reported many stressors including personal issues, match specific issues, and external factors that were attended to by a variety of coping strategies including social support, reflection, and self-talk. In sum, the aforementioned literature has illustrated provisional links between stressors and the implemented coping strategies, however future researchers need to explore: 1) the entire SEC process through an approach that encapsulates each component as an interdependent transaction; and, 2) the coping strategies used to manipulate the stress and emotion experience to enable the prevalence of helpful behaviors (e.g., Thelwell et al., 2007; Weston et al., 2009).

Building on the research that isolated the individual components of the SEC process, several scholars have taken a holistic approach and examined more of the SEC process (e.g., Neil, Bayston, Hanton, \& Wilson, 2013a; Neil, Hanton, Mellalieu, \& Fletcher, 2011; Nicholls, Polman, \& Levy, 2012). To illustrate, Nicholls and associates used path analysis and highlighted a sequential account of SEC experiences. Their data supported the notion that stressors, appraisals, emotions, and coping are highly related constructs. Using a qualitative approach, Neil and colleagues (2011) provided insight into the transaction of both male and female athletes across multiple sporting environments through interviews and single-case procedures. The data revealed the relationship between initial appraisals, emotions, further appraisals, and subsequent behavior, emphasizing the different influence of athletes' appraisals on their emotional response(s). Further, athletes who viewed their emotional response as positive increased their effort and concentration, and enhanced performance. In contrast, athletes who viewed emotions as detrimental described performing poorly. Similarly, Neil and colleagues (2013a) examined the influence of stress and emotions on referee decisionmaking through identifying the stressors encountered, the consequent appraisals, emotions, and adopted coping strategies. Data highlighted the use of problem-focused and emotion-focused coping strategies to deal with the negative appraisals and associated emotions, a process that enabled better decision-making.

Qualitative designs such as the one adopted by Neil and colleagues $(2011 ; 2013 \mathrm{a})$ have been advocated to explore the "theoretical heart" of the SEC process (Lazarus, 1991, p. 61). Despite this emerging body of work providing a more holistic insight into the SEC process and the impact on performance behavior, studies have typically adopted a snapshot approach through retrospective methods. That is, they have considered one transaction at one moment in time, failing to consider the ongoing intricacies of a person's stress experience(s). To highlight the reciprocal nature of the SEC process, future researchers may adopt temporal methods to further understand athletes' experiences (Hanton et al., 2012). Such approaches would highlight the sport-specific experiences of athletes and give insight into the stressors, appraisals, emotions, coping strategies, and behavioral responses associated with sports performance over time.

Adhering to the aforementioned recommendations the current study adds to the extant literature by providing a more representative account of Lazarus' conceptualization of SEC through adopting a temporal and holistic examination of cricketers' SEC experiences. Specifically, we aimed to highlight the SEC process in its entirety with a view to extending the provisional links demonstrated in the stress and coping research (e.g., Devonport et al., 2013; Thelwell et al., 2007; Weston et al., 2009). Therefore, in this study we explored the stressors, cognitions, emotions, coping strategies, and behaviors that elite cricketers experienced throughout the 7-day period leading up to and on the day of their first competitive fixture of the season.

\section{Method}

\section{Participants}

Upon obtaining ethical approval from the University ethics board, we used a purposive sampling approach consistent with recent SEC literature to obtain the sample for this study (e.g., Hanton, Wagstaff, \& Fletcher, 2012; Neil et al., 2011). The lead author initially approached the Cricket Team's management to gain preliminary access to their players. With the approval of the Cricket Team's management, the lead author then gave a formal presentation to explain the study. Specifically, the presentation included an outline of the our interest in 
understanding the SEC experiences of elite cricketers, and how these experiences influenced elite cricketers' behaviors in the 7-day period leading up to and on the day of their first competitive fixture of the season. After verbally agreeing to participate in the study, four elite male cricketers with ages ranging from 20 to $23(M=21.25, S D$ $=1.5$ ) provided written informed consent to participate in this study.

\section{Data Collection}

\section{Stress and Emotion Diaries.}

We collected data from the cricketers through diaries completed for a 7-day precompetition period and on the day of the Cricket Team's first competitive fixture of the season. Using diaries has been described as essential in capturing the temporal and dynamic nature of the SEC process (Lazarus, 2000). More specifically, we required an intensive monitoring process to illustrate the plethora of demands an individual may encounter each day, the meaning they ascribe to these encounters, and their attempts to cope (Dewe \& Trenberth, 2004). Consistent with previous research (e.g., Hanton et al., 2012; Neil, Hanton, \& Mellalieu, 2013b), we developed a standardized $\log$ for this study. The Stress and Emotion Diaries (SEDs) included a page for each day that prompted the players to record stressors that had affected their emotional state during each day. To reduce issues relating to retrospective recall the cricketers completed the SEDs at the end of each day (i.e., before getting ready for sleep; Campbell \& Jones, 2002). When recording the stressors, we prompted the participants to report their cognitions concerning the stressor (e.g., specifically, what were you thinking in relation to the stressor?) and the resultant emotions (e.g., how did this stressor make you feel?). Before issuing the SEDs, the lead author explained the requirements of the data collection process and provided the participants with an information sheet containing example diary entries. During data collection, the lead researcher attended the Cricket Team's training each day to answer any questions and help ensure adherence (e.g., Hanton et al., 2012; Nicholls et al., 2005[AUQ1]).

\section{Collection of Video Footage.}

To promote accurate recall and reflection during competition, video footage of each participant during competition was collected to use alongside postcompetition interviews. This approach has previously been successful in providing a stimulus to encourage more vivid recollections (e.g., Miles \& Neil, 2013; Smith \& Harwood, 2002). With the Cricket Club's approval, the lead author recorded footage of the competition on location using a $50 \mathrm{~Hz}$ camera situated directly behind the wicket from the media end of the ground (Miles \& Neil, 2013).

\section{Video Editing.}

To explore the participants' SEC experiences, we used Sportscode to edit the video into 15-s clips representing each competitive stressor identified within the SEDs. For all the participants, footage was also provided of the warm up, taking the field, and bowling or batting performances.

\section{Interview Process.}

We interviewed the cricketers the day after competition to reduce issues with retrospective recall. For the purpose of this study, we deemed an open-ended, semistructured interview technique as most appropriate to enable us to explore newly emerging themes while gaining greater clarification and understanding of participants' experiences (Patton, 2002). We tailored the interview guides for each participant in-line with the data collected from the SEDs and divided the interview guide into two sections. Section one contained a logical and progressive sequence of questioning encouraging the participants to elaborate on the stressors (e.g., "you mentioned the meeting was pointless, what made you record this?"), cognitions (e.g., "what specifically were you thinking when he told you this?"), emotions (e.g., "how would you describe the way you were feeling at this point?"), coping strategies (e.g., "what did you do to help cope with these thoughts and feelings?"), and behaviors (e.g., "how would you describe your behavior at this point?") emerging throughout the precompetition period. In sum, within the first section of the interview we explored the participants' SEC experiences throughout the 7-day period leading up to competition. In section two we focused on the participants' SEC experiences on the day of and during actual competition. To minimize issues surrounding retrospective recall that has limited previous studies within cricket (e.g., Thelwell et al., 2007), the questions regarding competitive experiences were accompanied by video footage of each participant during their performance.

\section{Pilot Studies.}

We piloted the SEDs with two recreational cricketers throughout a 3-day period leading up to competition. Following the pilot we made only cosmetic changes to the layout of the SEDs. The data collected over the 3-day period created a template for a pilot interview guide. Based on this template, the lead author then interviewed the same two recreational cricketers following competition. This process enabled the interviewer to become familiar with the type of responses the open-ended questions would provoke and ways to stimulate detailed descriptions (Flick, Kardorff, \& Steinke, 2004). We made minor amendments to the interview guide following the pilot to promote better clarification (e.g., 'I'm not entirely sure what you mean, could you please go over that again?') and elaboration (e.g., "could you please explain that in more detail?").

\section{Data Analysis}

Following all the interviews being transcribed verbatim, the lead author sent copies of the transcripts to the participants. This process enabled the participants to reflect on the interview and ensure the transcripts represented a valid description of events. Following confirmation from the participants that the transcriptions were accurate, we read and reread the transcripts to improve our 
understanding of each of the participants' unique experiences (Kvale, 2009). In-line with previous research (e.g., Hanton et al., 2012), we identified and coded words, phrases, and quotes associated with the stressors each participant encountered and the associated cognitions, emotions, coping strategies, and behavioral responses. We then conducted inductive and deductive content analyses (Côté, Salmela, Baria, \& Russell, 1993), with key components categorized into a Microsoft Excel document (Meyer \& Avery, 2009). To elaborate, the stressors and the associated cognitions, emotions, coping strategies, and behavioral responses were inductively analyzed into manageable meaning units (Côté et al., 1993) before being classified through deductive means in line with previous literature-consequently adopting a postpositivistic approach. For example, we categorized the stressors into competitive, organizational, and personal subcategories in line with existing stress literature (see Fletcher, Hanton, \& Mellalieu, 2006). We organized the cognitions and emotions using Lazarus's (2000) existing categories; while the coping strategies were also classified using Lazarus's (1999) model of coping that has been widely adopted within the sport literature (Nicholls \& Polman, 2007). Finally, the emanating behaviors remained inductively organized and were recorded as quotes from each participant. We then sent the raw data in the Microsoft Excel document and the first draft of the results section of this paper to the participants for member-checking procedures which verified our interpretations of the data.

\section{Results}

The data we collected highlights the types of stressors and subsequent cognitive, emotional, coping, and behavioral responses that elite cricketers experienced throughout the 7-day precompetition period and on the day of their first competitive fixture of the season. To clearly represent the large amount of data gathered during this study, we display the data through temporal representations using Microsoft Visio (see Figures 1-4). The representations give details of: the stressors; the associated cognitions; the subsequent emotions; the coping strategies; and the behavioral outcomes. To facilitate a contextual understanding and provide an empathetic view of the collective experiences of the players, we accompany these representations with a selection of narrative and descriptive quotes (Smith \& Sparkes, 2005).

k $<<<$ INSERT FIGURE 1, FIGURE 2, FIGURE 3 , AND FIGURE 4 ABOUT HERE $>>>>1$

\section{Precompetition Period}

From the 68 stressors recorded throughout the precompetition period (see Figures 1-4), 55 of the preceding SEC transactions concerned performance stressors. All the players identified cognitions associated with a variety of performance stressors that resulted in either positive or negative emotions, attempts to cope, and behavioral responses. To guide the reader through our findings, we describe the players' experiences in four stages of the week leading up to, and including, competition: 1) early in the week (Day 1-3); 2) throughout the middle of the week (Day 4-6); 3) the day before competition (Day 7); and 4) the day of competition. In each stage we illustrate the most frequently encountered stressors and the subsequent components of the SEC process.

\section{Day 1-3}

Early in the week, the most frequently cited competitive stressor by each player was team practice (including a practice fixture). When given the opportunity to elaborate on his experiences, Player C (Figure 3, Day 1) highlighted practice to be a commonly reported stressor and his attempts to cope:

I know it is important to perform well in practice to show the coaches that I have improved throughout the winter [stressor]. I often think about the importance of hitting the ball well leading up to the first class match as it increases your chances of selection [threat appraisal]. This leaves me feeling slightly anxious [emotion]. When you are feeling like this it is important to try and relax and watch the ball. This is something I will say to myself, 'relax and watch ball' during batting practice as it helps me focus [problem-focused coping] and, on this occasion during practice, I played well [performance behavior].

The above quotation highlights the importance of displaying competence at each practice to help the players achieve their overall goal of being selected for the competition. The potential of performing poorly in practice was appraised as threatening in relation to the chances of selection. In line with this appraisal and the associated anxiety response, all of the players reported the value of coping. Precompetition routine was the most commonly used coping strategy to regulate anxiety and redirect focus to the task. For example, Player B reported that he would focus on "the routine that [he] would use in the match" before going into bat (Figure 2, Day 1). He continued, "...when you are feeling under pressure and anxious, it is important that you have one constant routine that enables you to feel relaxed and focused". Although the components of each players precompetition routines were different, emphasis was placed on a systematic and "consistent routine" to cope with these demands.

Although practice was the most commonly cited stressor throughout the week, demands from outside of cricket were noted to affect the players' cognitions, emotions, and behaviors at the start of the precompetition period. On Day 2, Player A reported that he had recently broken up with his girlfriend and noticed himself becoming particularly aware of his demands:

The break up made me realize I am at a big crossroad in my life [stressor]. I don't know what will come after university... Will I play cricket? Will I get a job? Will I get back with my girlfriend? Will I be living away from home? It seems like I have a lot on 
my plate and I'm not sure how I'm going to handle it, let alone focus on the match at the weekend [threat appraisal].

Feeling increasingly anxious [emotion], Player A returned home to use his social support networks. By confiding in his family, he was able to gain some perspective on his situation [emotional coping] and appeared much more sociable and attentive [behavior] (Figure 1, Day 2). When we asked Player A how he was feeling the next morning, he responded positively:

In the morning, all the worrying thoughts had gone and I was looking forward to our practice fixture [stressor]. I was thinking 'cricket is the most important thing in my life right now' [benefit appraisal] and I was really happy and looking forward to the day ahead [emotion]. I returned to my normal self [behavior].

Despite the temporary diversion of Player A's attention, he later stated that "those thoughts are still there, but being around the boys and striving for selection enabled me to cope with it". The above quotation illustrates the value of social support as an emotion-focused coping strategy and also highlights that cognitions can be diverted toward other important goals (e.g., the goal of being selected for competition).

\section{Day 4-6}

Although the players recorded personal issues and demands associated with displaying competence in practice, organizational stressors related to the coach's view on selection became more frequent as the week progressed. All of the players continually appraised their chances of selection as a consequence of coach perception. Indeed, the demand of selection was most often timed at night following the days practice. Half way through the week, three of the four players reported cognitions associated with their chances of selection. Player $\mathrm{C}$ provided insight into the general thoughts of the group on Day 4:

What the coach thinks of you [stressor] and where he sees your role in the team is particularly concerning [threat appraisal]. You often end up feeling anxious and frustrated [emotion] no matter how much reassurance you get from your teammates throughout the week [emotion-focused coping]. Most evenings I would find myself sitting in my room rather than socializing with my housemates [behavior].

The above quotation shows Player C's view on selection in relation to coach perception(s) and the rationale for many of the cognitions that the players had throughout the week. Regardless of how the players viewed their practice throughout the week, organizational stressors concerning the uncertainty of the coach's opinion was appraised as a threat given the importance of their selection for competition.

Toward the end of the week there were several occasions when the players highlighted stressors that were perceived to enhance or diminish team values before competition. To elaborate, player D illustrated an occasion on Day 5 where several players jeopardized team values by wearing the wrong kit, which threatened the prospects of a good practice session (Figure 4):

Three or four of the boys weren't wearing the right clothing and as soon as they walked into the meeting you could see that the coach wasn't impressed [stressor]. This was reflected by a poor start to our warm ups and could have led on to a bad net session [harm appraisal]. Given how close we were to competition, this made me angry [emotion]. I knew getting angry wouldn't help so I started to joke with one of the lads that was wearing the wrong kit [emotion-focused coping]. This helped my body language in the session [behavior] and, slowly, the atmosphere improved.

The use of humor was highlighted on several occasions to enable coping with team-related organizational stressors. To elaborate, Player A explained why he used humor to cope with one of his teammates making him late for practice on Day 6 (Figure 1):

We jokingly, yet seriously, let him know that we were annoyed. For example, we were swearing and saying he's always late. Although I was annoyed, having a joke made it a little easier. I think it gets the message across without causing too many issues. I hope that he takes it well but learns his lesson from it. If I didn't make a joke of it, it would have festered and I may have taken it out on him later.

Both of these explanations highlight how the players used humor within the team environment to maintain a positive team ethos while ensuring that their teammates were aware of their misdemeanors.

\section{The Day Before Competition (Day 7)}

At the end of the week, three of the four players (A, B, and D) were selected for the competition. Although Player $C$ missed out on selection for the competition, he was named as 12 th man. Given that the role of 12 th man required Player $\mathrm{C}$ to be present at the competition, his experiences were recorded (Figure 3, Competition). Upon receiving news of selection, all three of the selected players reflected upon their week's preparation. Depending on the perception of their performances throughout the week, the resultant cognitions represented a benefit or threat appraisal and subsequently positive (i.e., happiness) or negative (i.e., anxiety) emotions. To elaborate, player D provided insight into the experience he had on the night before competition (Figure 4, Day 7):

I knew that I had been training well [stressor] all week and that gives you such a confidence boost [benefit appraisal]. Reflecting on this made me feel really happy [emotion] and confident going into the game. Despite these thoughts, you sometimes find yourself thinking about letting yourself and your team down [threat appraisal]. To counter this, I would tell to myself, 'you know you are up to pace' 
and that helped me a lot as the game was so close [problem-focused coping]. Despite the bursts of anxiety, I was very happy [emotions] about my chances the next day and as a result I was buzzing and full of energy whilst sat with my housemates [behavior].

The above quotation highlights the continual and fluctuating nature of the SEC process. In addition, it highlights the use of positive reminders, through the use of self-talk, as a form of coping to negate any feelings of anxiety. In particular, the players would appear to find positives in stressors that were initially deemed to be threatening (e.g., past performances in practice).

\section{Day of Competition}

Upon waking up on the morning of the competition, the players recorded their thoughts surrounding the approaching competition [stressor]. Having spent the majority of the week with concerns over selection, all the players initially appraised the competition as a great occasion [benefit appraisal] that they could enjoy. Typically, all of the players reported feelings of happiness [emotion] at the start of the day. Specifically, the players drew upon their week's preparation as a source of confidence to explain their feelings. To illustrate, Player A stated:

Despite all the ups and downs you have in the week with thoughts concerning your performance in practice, you actually become stronger and more confident as a result. Being able to draw on this will be important as the day goes on; it will particularly help when you are put on the spot to perform [when batting or bowling].

The sentiments provided above were consistent with the three players who had made the team for competition. However, as the morning progressed, it was apparent that the players' goals had changed from gaining selection to performing well in the competition. For example, Player A gave more insight into this change:

For players on this scheme there are no bigger games than this. I think most of the players would agree that this is the most important match of the season [stressor]... Your focus changes quickly from getting in the team to wanting to play well... It becomes important that you play well to make a name for yourself [threat appraisal].

To cope with the anxiety associated with their approaching performance, all three of the cricketers who were selected for competition focused on their precompetition preparation and routines [problem-focused coping]. Player B advocated the use of a precompetition routine as it helped "stop any negative thoughts creeping in and focused [him] on the task at hand". As a result he was "very focused" in the morning's warm-ups and executed his precompetition preparation "really well" [behavior].

Specific to competition, the three selected players (A, $\mathrm{B}$, and $\mathrm{D})$ reported different stressors associated to their individual roles. To elaborate, Player A gave insight into being asked to bowl by the captain (Figure 1, Competition):

I had been waiting for about 45 minutes when the captain asked me to bowl [stressor]. Although you want to be excited, you can't help but feel anxious [emotion] about the occasion given that you don't want to fail [threat appraisal]. By concentrating on my pre-competition routine it helped me focus on my skills rather than all the other thoughts you get [problem-focused coping]. With my first ball, I fully committed to my routine and I got a wicket [competition behavior].

Player A was not alone in his use of precompetition routines to help him cope with the demands of competition. All three participants reported precompetition routines as a valuable coping strategy during competition, as it enabled them to focus on their skills as well as relax during times of increased anxiety. In addition, during periods of selfdoubt, the players used self-talk as a reminder of their preparation throughout the week and their readiness to compete.

\section{Discussion}

This study adds to the extant literature by becoming the first to provide a holistic and temporal exploration of the SEC process underpinned by the CMR theory of emotions (Lazarus, 1999). By addressing the call for more temporal designs to explore the SEC process (Hanton et al., 2012), we have demonstrated some of the SEC experiences of elite cricketers throughout a 7-day precompetition period and on the day of the first competitive fixture of the season. These data provide insight into the transactions that cricketers have with their environment through: the stressors, cognitions, emotions, coping strategies, and eventual behavioral responses in the lead up to an important competition. Consequently, data support existing literature that illustrated athletes face a diversity of demands, appraise each demand in relation to their existing goals, experience a myriad of emotions, and attempt to cope through a number of different strategies, all of which ultimately affect performance behaviors (Neil et al., 2011; 2013b).

While the narratives provide specific insight into the SEC transactions that arise during the lead up to, and during, competition, the temporal representations (see Figures 1-4) also illustrate the ongoing and continuous nature of the SEC process over a prolonged period of time. Specifically, the players in this study reported a number of stressors across the week, some of which reoccurred in line with their existing performance goals. Despite the emphasis on performance stressors, the players continued to experience stressors that emanated from outside the performance environment (Hanton, Fletcher, \& Coughlan, 2005; Woodman \& Hardy, 2001). That is, organizational (e.g., team issues) and personal (e.g., relationships) stressors that evoked a number of cognitions, emotions, coping responses, and behavioral outcomes. Indeed, our 
data illustrate the need for athletes to continuously cope with numerous demands from a variety of contexts to avoid conflict with their most salient goals (e.g., Fletcher et al., 2006; Mellalieu, Neil, Hanton, \& Fletcher, 2009).

To cope with the stressors and the resulting cognitive and emotional responses, the players reported using several coping strategies. Consistent with the CMR theory of emotions, the coping strategies were implemented during threat and harm appraisals (including negative emotional responses; Lazarus, 2000). In particular, the players expressed the use of precompetition routines, social support, self-talk, and humor (e.g., Cotterill, 2011; Gaudreau, Blondin, \& Lapierre, 2002; Miles \& Neil, 2013; Thelwell, Weston, \& Greenless, 2007). Although the type of coping strategy used was specific and unique to each player's appraisal, analysis of the data revealed several common strategies. For example, precompetition routines were regularly used to help cope with many of the competitive stressors appraised as threatening (i.e., the need to display competence) and evoked emotions perceived as detrimental to competition (i.e., anxiety). Previous research on stress and coping in cricket has revealed the importance of prematch preparatory strategies to help overcome stress from self-induced pressure and match-specific issues (Thelwell et al., 2007), a result that is congruent with data in our study. Although existing research has indicated the effectiveness of preperformance routines on skill execution (e.g., Cotterill, 2011), future researchers should continue to adopt more experimental methodologies to explain why preperformance routines assist performers in regulating the affects of the SEC process on skill execution.

Regarding organizational or personal stressors that were appraised as threatening or harmful to goal attainment, the players highlighted the value of social support networks and the use of humor as useful coping strategies. Indeed, athletes have been reported to seek support agencies comprising of teammates and coaches for instrumental and emotional purposes (Bianco, 2001). Although our study provides examples of using teammates as social support for concerns surrounding selection, the data also offer evidence for the use of support networks external to the sports organization (e.g., friends and family). The data indicate providers of social support (from outside of cricket) were used more frequently as an emotion-focused coping strategy since consulting with teammates or coaches was seen to have potential implications for future selection (Bianco, 2001). These data align with previous research exploring the efficacy of Personal-Disclosure Mutual-Sharing (PDMS) intervention strategies on team functioning variables (e.g., Barker, Evans, Coffee, Slater, \& McCarthy, 2014). Through the use of PDMS, practitioners may aim to enhance the quality of relationships and rapport among teammates and coaching staff to further enhance the provision of emotional support. Similarly, the data from our study also highlight humor as a potential coping strategy for team-related issues. Comparable to the data of our study, the use of humor has recently been described as a specific interpersonal emotion regulation strategy used in competitive situations (Tamminen \& Crocker, 2013). Therefore our preliminary data may provide a valuable avenue for future researchers interested in understanding coping strategies to maintain social relationships in the sport environment (Niven, Totterdall, \& Holman, 2009).

The strength of this present study is based upon the combination of qualitative techniques to more effectively understand the experiences of elite cricketers in the period leading up to, and during, competition. Advancing on retrospective inquiry, we gave the participants opportunity to reflect upon, and record, their SEC experiences through the use of diaries (e.g., Hanton et al., 2012). In addition, we used innovative methods to delineate the players' SEC experiences over a prolonged and significant period of time before competition. By adopting this approach, we have demonstrated the ongoing and continuous nature of SEC (Lazarus, 1999; 2000), and have highlighted the idiosyncratic nature of each SEC response is underpinned by unique athlete goals. While our data have reinforced the credentials of the CMR theory of emotions (Lazarus, 2000), we acknowledge that this study only provides provisional insight into the athletes' goals and their SEC response in relation to performance behaviors. Future researchers should consider investigating the specific goals of athletes, their cognitive and emotional responses, and the effectiveness of specific coping strategies (e.g., self-talk) on athletic performance.

In conclusion, this study is the first to provide a holistic and temporal exploration of SEC underpinned by the CMR theory of emotions (Lazarus, 1999). Through exploring the SEC experiences of elite cricketers, data indicate a variety of stressors and subsequent cognitive, emotional, coping, and behavioral responses. In particular, our data support the ongoing and continuous nature of the SEC process and highlight the central role of appraisals (Lazarus, 1999). By using an approach that illuminated the SEC process in its entirety, we have shown the types of coping strategies that cricketers use to regulate their stress experiences and performance behavior(s). Thus, future researchers are encouraged to adopt experimental approaches to examine the effectiveness of these coping strategies on actual athletic performance.

\section{References}

Barker, J., Evans, A.L., Coffee, P., Slater, M., \& McCarthy, P.J. (2014). Consulting on tour: A multiple-phase personal-disclosure mutualsharing intervention and group functioning in elite youth cricket. The Sport Psychologist, 28, 186197. doi:10.1123/tsp.2013-0042

Bianco, T. (2001). Social support and the recovery from sport injury: Elite skiers share their experiences. Research Quarterly for Exercise and Sport, 72, 376-388. PubMed doi:10.1080/02701367.2001.10608974

Campbell, E., \& Jones, G. (2002). Cognitive appraisal of sources of stress experienced by elite male 
wheelchair basketball players. Adapted Physical Activity Quarterly, 19, 100-110.

Corbin, J., \& Strauss, A. (2008). Basics of qualitative research: techniques and procedures for developing grounded theory (3rd ed.). Thousand Oaks, California: Sage.

Côté, J., Salmela, J.H., Baria, A., \& Russell, S.J. (1993). Organizing and interpreting unstructured qualitative data. The Sport Psychologist, 7, 127-137.

Cotterill, S.T. (2011). Experiences of developing precompetition routines with elite cricket players. Journal of Sport Psychology in Action, 2, 81-91. doi:10.1080/21520704.2011.584245

Devonport, T.J., Lane, A.M., \& Biscombe, K. (2013). Exploring coping strategies used by national adolescent netball players across domains. Journal of Clinical Sports Psychology, 7, 161-177.

Dewe, P.J., \& Trenberth, L. (2004). Work stress and coping: Drawing together research and practice. British Journal of Guidance \& Counselling, 32, 139142. doi: $10.1080 / 03069880410001693138$

Fletcher, D., Hanton, S., \& Mellalieu, S.D. (2006). An organizational stress review: Conceptual and theoretical issues in competitive sport. In $\mathrm{S}$. Hanton \& S.D. Mellalieu (Eds.), Literature reviews in sport psychology (pp. 321-374). Hauppauge, NY: Nova Science.

Flick, W., Kardorff, E.V., \& Steinke, I. (2004). A companion to qualitative research. London, UK: Sage.

Gaudreau, P., Blondin, J-P., \& Lapierre, A-M. (2002). Athletes' coping during a competition: relationship of coping strategies with positive affect, negative affect, and competition-goal discrepancy. Psychology of Sport and Exercise, 3, 125-150. doi:10.1016/S1469-0292(01)00015-2

Hanton, S., Fletcher, D., \& Coughlan, G. (2005). Stress in elite sport players: A comparative study of competitive and organizational stressors. Journal of Sports Sciences, 23, 1129-1141. PubMed doi:10.1080/02640410500131480

Hanton, S., Neil, R., \& Mellalieu, S.D. (2008). Recent developments in competitive anxiety direction and competition stress research. International Review of Sport and Exercise Psychology, 1, 45-57. doi:10.1080/17509840701827445

Hanton, S., Wagstaff, C.R.D., \& Fletcher, D. (2012). Cognitive appraisals of stressors encountered in sport organizations. International Journal of Sport and Exercise Psychology, 10, 276-289. doi:10.1080/1612197X.2012.682376

Kvale, S. (2009). Doing Interviews. London, UK: Sage.

Lazarus, R.S. (1991). Emotion and adaptation. New York, NY: Oxford University Press.

Lazarus, R.S. (1999). Stress and emotion: A new synthesis. London, UK: Free Association.

Lazarus, R.S. (2000). How emotions influence competition in competitive sports. The Sport Psychologist, 14, 229-252.

Lazarus, R.S., \& Folkman, S. (1984). Stress, appraisal, and coping. New York, NY: Springer.
Mellalieu, S.D., Neil, R., Hanton, S., \& Fletcher, D. (2009). Competition stress in sport players: stressors experienced in the competition environment. Journal of Sports Sciences, 27, 729744. PubMed doi:10.1080/02640410902889834

Meyer, D.Z., \& Avery, L.M. (2009). Excel as a qualitative data analysis tool. Field Methods, 21, 91-112. doi:10.1177/1525822X08323985

Miles, A.J., \& Neil, R. (2013). The use of self-talk during elite cricket batting competition. Psychology of Sport and Exercise, 14, 874-881. doi:10.1016/j.psychsport.2013.07.005

Neil, R., Bayston, P., Hanton, S., \& Wilson, K. (2013a). The influence of stress and emotions on association football referees' decision-making. Sport \& Exercise Psychology Review, 9, 22-41.

Neil, R., Fletcher, D., Hanton, S., \& Mellalieu, S.D. (2007). (Re)conceptualizing competition stress in sport players. Sport \& Exercise Psychology Review, 3, 23-29.

Neil, R., Hanton, S., \& Mellalieu, S.D. (2013b). Seeing things in a different light: Assessing the effects of a cognitive-behavioral intervention upon the further appraisals of golfers. Journal of Applied Sport Psychology, 25, 106-130. doi:10.1080/10413200.2012.658901

Neil, R., Hanton, S., Mellalieu, S.D., \& Fletcher, D. (2011). Competition stress and emotion in sport players: The role of further appraisals. Psychology of Sport and Exercise, 12, 460-470. doi:10.1016/j.psychsport.2011.02.001

Nicholls, A.R., \& Polman, R. (2007). Coping in sport: A systematic review. Journal of Sports Sciences, 25, 11-31. PubMed doi:10.1080/02640410600630654

Nicholls, A.R., Polman, C.J., \& Levy, A.R. (2012). A path analysis of stress appraisals, emotions, coping, and competition satisfaction among athletes. Psychology of Sport and Exercise, 13, 263270. doi:10.1016/j.psychsport.2011.12.003

Niven, K., Totterdall, P., \& Holman, D. (2009). A classification of controlled interpersonal affect regulation strategies. Emotion (Washington, D.C.), 9, 498-509. PubMed doi:10.1037/a0015962

Patton, M.Q. (2002). Qualitative research and evaluative methods (3rd ed.). London, UK: Sage.

Smith, J.M.J., \& Harwood, C.G. (2002). The transiency of goal involvement states within match-play: A case study of an elite player. Journal of Sports Sciences, 20, 71-72.

Smith, B., \& Sparkes, A.C. (2005). Analyzing talk in qualitative inquiry: exploring possibilities, problems, and tensions. Quest, 57, 213-242. doi:10.1080/00336297.2005.10491854

Tamminen, K.A., \& Crocker, P.R. (2013). "I control my own emotions for the sake of the team": Emotional self-regulation and interpersonal emotion regulation among female highperformance curlers. Psychology of Sport and Exercise, 14, 737-747. doi:10.1016/j.psychsport.2013.05.002

Thelwell, R.C., Weston, N.J.V., \& Greenless, I.A. (2007). Batting on a sticky wicket: Identifying 
sources of stress and associated coping strategies for professional cricket batsmen. Psychology of Sport and Exercise, 8, 219-232. doi:10.1016/j.psychsport.2006.04.002

Weston, N.J.V., Thelwell, R.C., Bond, S., \& Hutchings, N.V. (2009). Stress and coping in single-handed round-the-world ocean sailing. Journal of Applied doi:10.1080/104132001753149892
Sport Psychology, 21, 460-474. doi:10.1080/10413200903232607

Woodman, T., \& Hardy, L. (2001). A case study of organizational stress in elite sport. Journal of Applied Sport Psychology, 13, 207-238. 

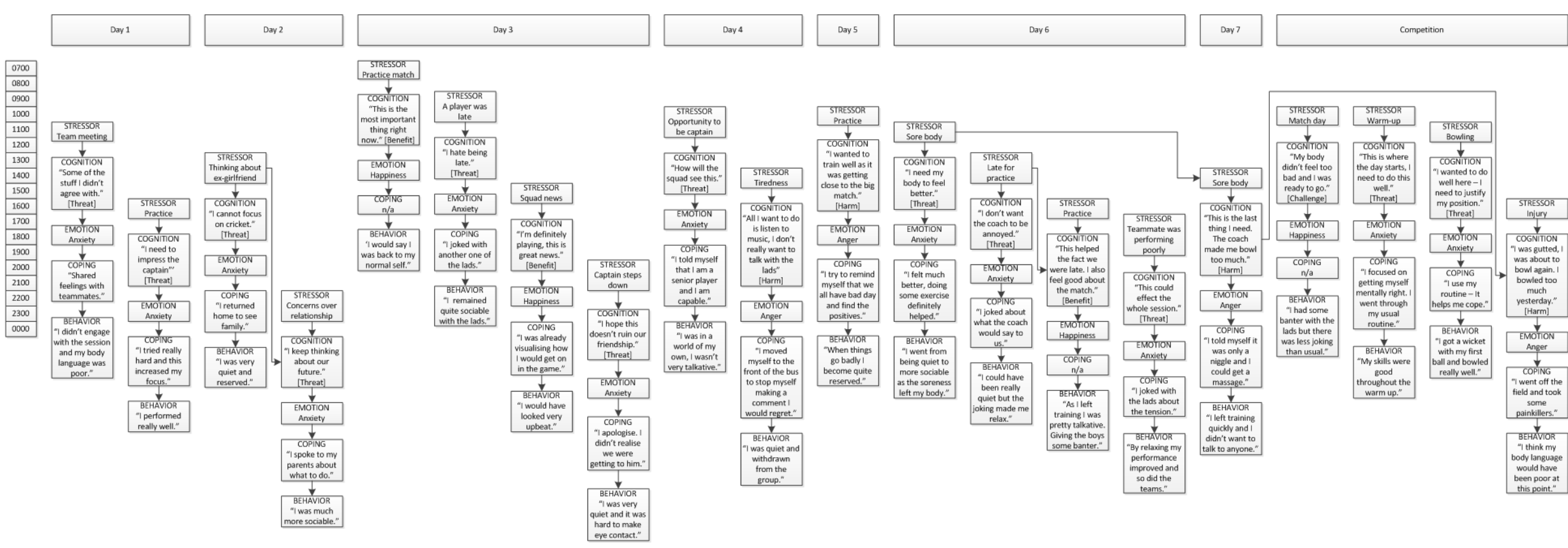

Figure 1 - Temporal representation of the stress and emotion process of the 8-day period leading up to, and including, competition for Player A. 


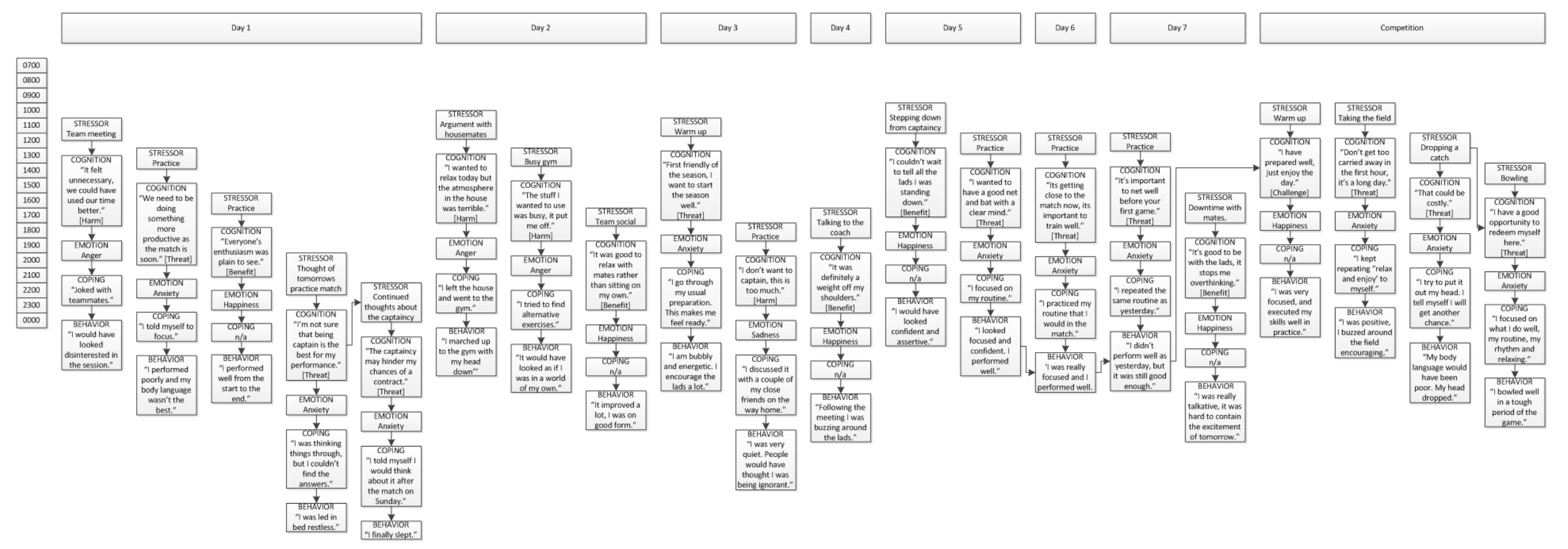

Figure 2 - Temporal representation of the stress and emotion process of the 8-day period leading up to, and including, competition for Player B. 


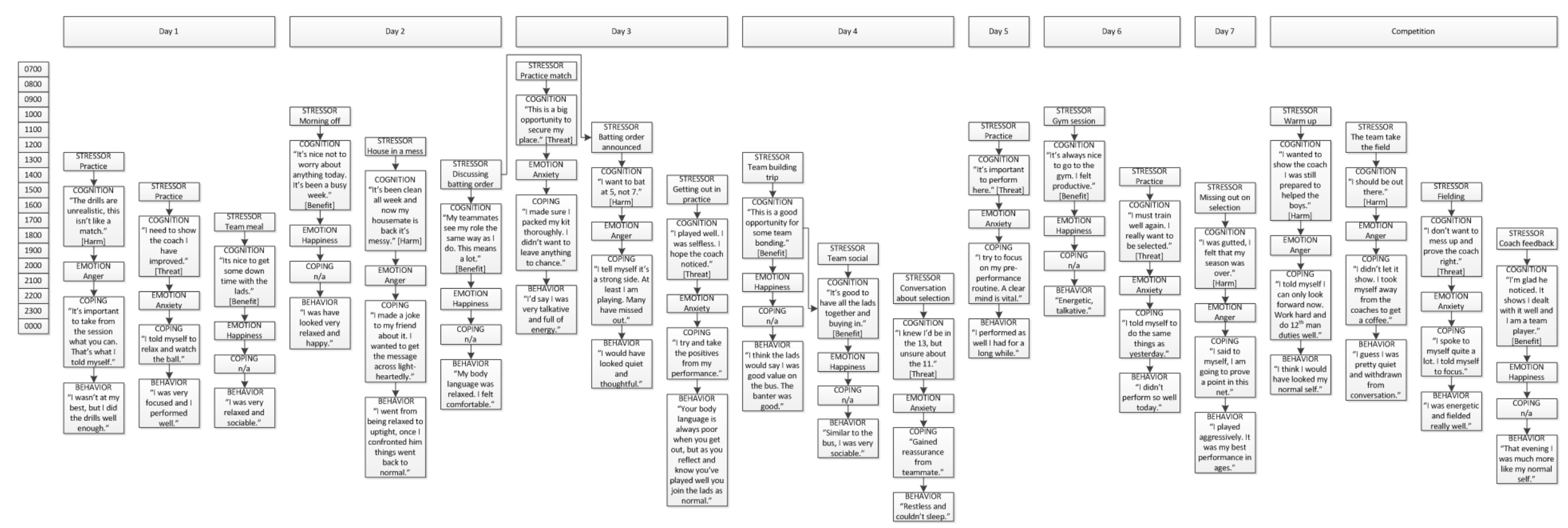

Figure 3 - Temporal representation of the stress and emotion process of the 8-day period leading up to, and including, competition for Player C. 


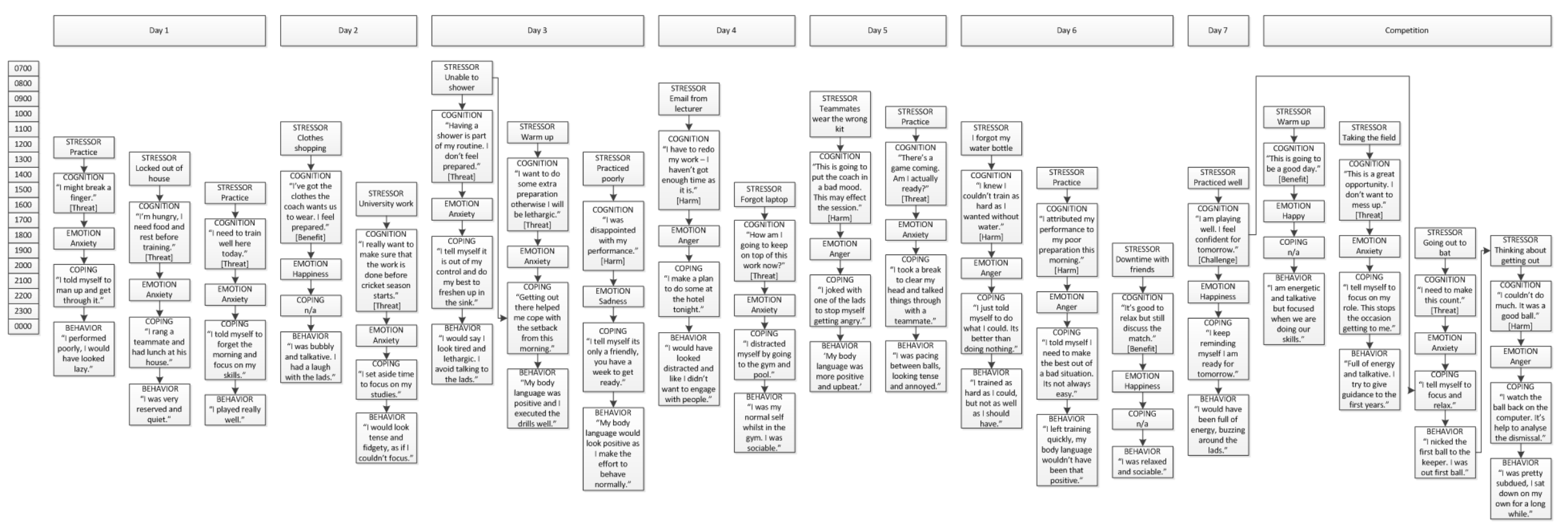

Figure 4 - Temporal representation of the stress and emotion process of the 8-day period leading up to, and including, competition for Player D. 


\section{Author Queries}

[AUQ1] The in-text citation "Nicholls et al., 2005" is not in the reference list. Please correct the citation, add the reference to the list, or delete the citation.

Page 5 of 14 